\title{
Influence of dietary CLA isomers and selenium compounds on the fatty acid and amino acid profiles in blood plasma of rats*
}

\author{
K.M. Niedźwiedzka, K. Korniluk, J. Kowalczyk and M. Czauderna ${ }^{1}$
}

\author{
The Kielanowski Institute of Animal Physiology and Nutrition, \\ Polish Academy of Sciences \\ 05-110 Jabłonna, Poland
}

(Received 5 April 2007; accepted 2 May 2007)

\begin{abstract}
The influence of diets enriched in CLA isomers and/or selenium on the concentration of fatty acids and amino acids in blood plasma was studied on 20 groups of 7-8 rats aged 8 weeks and with a body weight (BW) of about $201 \mathrm{~g}$. Rats were fed a basal diet for 29 days or a diet enriched with a combination of 1 or $2 \%$ CLA isomer(s) and/or 2 ppm as selenate, $1.2 \%$ as selenized yeast.

Diets enriched in $1 \%$ of $t 10$ c12CLA and Se compounds caused the most efficient body weight gain $(\mathrm{BWG})$ and feed conversion. Diets enriched in Se compounds only showed a tendency to decrease BWG and feed conversion efficiency compared with control rats. Diets with CLA isomers increased isomer concentrations in plasma with preferential accumulation $c 9$ t11CLA in comparison with $t 10 c 12$ CLA. Supplemental Se and CLA isomer mixture usually increased $\beta$-oxidation of t10c12CLA compared with supplementing the CLA isomer mixture only. Supplementing $1 \%$ of the CLA isomer mixture showed tendency to decrease the concentration of C16:0 and SFA in plasma but supplementing 1 or $2 \%$ of the isomer mixture with Se compounds tended to or significantly decreased $\mathrm{C} 16: 0$ and SFA in plasma. The $t 10 c 12 \mathrm{CLA}$ isomer reduced, whereas $c 9 t 11 \mathrm{CLA}$, stimulated the yield of $\Delta 9$-desaturation.

An increase of linoleic and linolenic acid concentrations was found in the plasma of rats fed the diet with CLA isomer(s) and Se sources compared with the control diet. Supplementing Se sources or CLA isomer(s) stimulated MUFA and PUFA accumulation in plasma due to stimulation of $\Delta 9-, \Delta 6$ - and $\Delta 4$-desaturation and elongation of fatty acids. Supplementing CLA isomers increased the concentration of amino acids in plasma, while the interaction between supplemented c9t11CLA and 110c12CLA in rats resulted in reduction of the concentration of amino acids in plasma.
\end{abstract}

KEY WORDS: CLA isomers, selenate, high-selenized yeast, fatty acids, amino acids, blood plasma, rat

\footnotetext{
* Supported in part by the Ministry for Science and Information, Grant No. 2 P06Z 01629

${ }^{1}$ Corresponding author: e-mail: m.czauderna@ifzz.pan.p1
} 


\section{INTRODUCTION}

Recent investigations have documented that conjugated linolenic acid (CLA) isomers could exert many beneficial effects on human health thanks to their antiproliferative, antitumour, antiinflammatory, antiatherogenic, antidiabetogenic, and antiadipogenic properties (Wahle et al., 2004; De La Tore et al., 2006). A beneficial regulatory influence of CLA isomers on cytokine and immunoglobulin production, and on immune function was found. CLA isomers affected the metabolisms of lipids and eicosanoids, as well as of other fatty acids (Naumann et al., 2006). Our recent studies also clearly evidence that dietary selenium (Se) and CLA isomers influenced the concentration of mono- (MUFA) and polyunsaturated (PUFA) fatty acids, minerals and amino acids in laboratory animals (Czauderna et al., 2004; Korniluk et al., 2006; Niedźwiedzka et al., 2006a,b). The nutritional requirements of animals and humans should met by provision of ultra-trace nutrients like Se or essential fatty acids. In humans and animals, numerous disorders related to Se have been recognized, including liver necrosis, white muscle dystrophy, exudative diathesis, and cardiomyopathy (Arthur, 2003; Lyons and Jacques, 2004). The discovery that Se was an essential component of radicalor/and peroxide-metabolizing seleno-proteins (e.g., glutathione peroxidase) led to the hypothesis that physiologically advantageous supplementation with $\mathrm{Se}$ results in elevation of unsaturated fatty acid concentrations in animals. Recent investigations revealed that dietary selenate and high-selenized yeast increased the accumulation of CLA isomers and other PUFA in the bodies of rats (Czauderna et al., 2004a,b). Therefore, a protective effect of dietary Se (seleno-cysteine is an essential component of more than 25 seleno-proteins) on the deposition of CLA isomers and other unsaturated fatty acids in the body of mammals may also be plausible.

Considering the above evidence, we decided to carry out experiments to test the hypothesis that dietary CLA isomer(s), inorganic and organic Se (as selenate and high-selenized yeast) improve the fatty acid profile in blood plasma of rats. The influence of diets enriched in CLA isomer(s) and Se on the concentrations of free essential (E-AA) and non-essential (NE-AA) amino acids in plasma and protein E-AA and NE-AA amino acids in the liver and femoral muscles was also examined. On the basis of these investigations we intended to compare the efficacy of dietary selenate $\left(\mathrm{Se}^{\mathrm{VI}}\right)$ and organic $\mathrm{Se}$ (Se-yeast) on the capacity for accumulation of CLA isomers, other unsaturated fatty acids and, in particular, E-AA in plasma, liver, and muscles. 


\section{MATERIAL AND METHODS}

\section{Animals and experimental design}

The experimental protocol was approved by the Local Animal Care and Use Committee (The Agricultural University, Warsaw, Poland).

Ten groups of 7-8 female rats (Wistar, Ifz: BOA), at 8 weeks of age, each weighing $201 \pm 1 \mathrm{~g}$ at the beginning of the experiment, were housed individually in plastic cages at a temperature of $22 \pm 1^{\circ} \mathrm{C}$ with a $12 \mathrm{~h}$ light-dark cycle and relative humidity of 50-60\%. During a one-week preliminary period the animals were fed a standard Labofeed $\mathrm{H}$ diet produced by the Feeds and Concentrates Production Plant in Kcynia, (Poland) (Pastuszewska et al., 2000) given at a submaintenance level ( $9 \mathrm{~g}$ of diet daily per rat) to reduce body fat content. During that time the rats decreased their body weight by about $10 \%$ of their initial weight. Then for 29 days the rats were fed the experimental diets (Table 1) enriched with 1 or $2 \%$ of the mixture of CLA isomers (CLAmix), $1 \%$ of individual isomers (i.e. $c 9 t 11$ and $t 10 c 12$ ), 2 ppm Se as $\mathrm{Se}^{\mathrm{VI}}$ (Experiment I) or 1.2 ppm Se as Se-yeast (Experiment II). The composition of dietary CLA isomer(s) is presented in Table 1. The rations were adjusted each day to ensure an ad libitum feeding level. After day 29 rats were killed by $\mathrm{CO}_{2}$ and the liver and femoral muscles removed and freeze-dried. Blood samples were collected into heparinized tubes kept in an ice bath and centrifuged at $1500-1700 \mathrm{~g}$ for $15 \mathrm{~min}\left(\right.$ at $2-4^{\circ} \mathrm{C}$ ). Muscle, liver and blood plasma samples were stored at $-28^{\circ} \mathrm{C}$ until analysed for the concentrations of fatty acids and amino acids.

\section{Reagents and chemicals}

Sodium selenate $\left(\mathrm{Na}_{2} \mathrm{SeO}_{4}\right)$ and amino acid (AA) standards were provided by Sigma (USA), whereas methanol, 99.9\% acetonitrile and 95\% heptane were HPLC grade and purchased from Lab-Scan (Ireland). The CLA isomer mixture (CLAmix), c9t11CLA and $t 10 c 12 \mathrm{CLA}$ isomers were supplied by Larodan Fine Chemicals AB (Sweden). Composition details (Table 1) and the purity of CLA isomer mixtures and individual isomers were examined using our $\mathrm{Ag}^{+}$-HPLC and GLC method (Czauderna et al., 2003, 2005).

All fatty acid (FA) standards, $50 \% \mathrm{BF}_{3}$ in methanol, o-phthaldialdehyde (OPA) and butylated hydroxytoluene were provided by SIGMA (USA) and Suppelco. Ethanethiol, tetrahydrofuran and sodium hypochlorite water solution $(4 \%$ available $\mathrm{Cl})$ were from Fluka. High-selenized yeast (Se-yeast) was donated by Sel-Plex (Alltech Inc., USA). Eighty-three per cent of the total Se content of Se-yeast represents Se in the form of Se-methionine incorporated into the proteins of Saccharomyces cerevisiae (Rayman, 2004). Other reagents, 


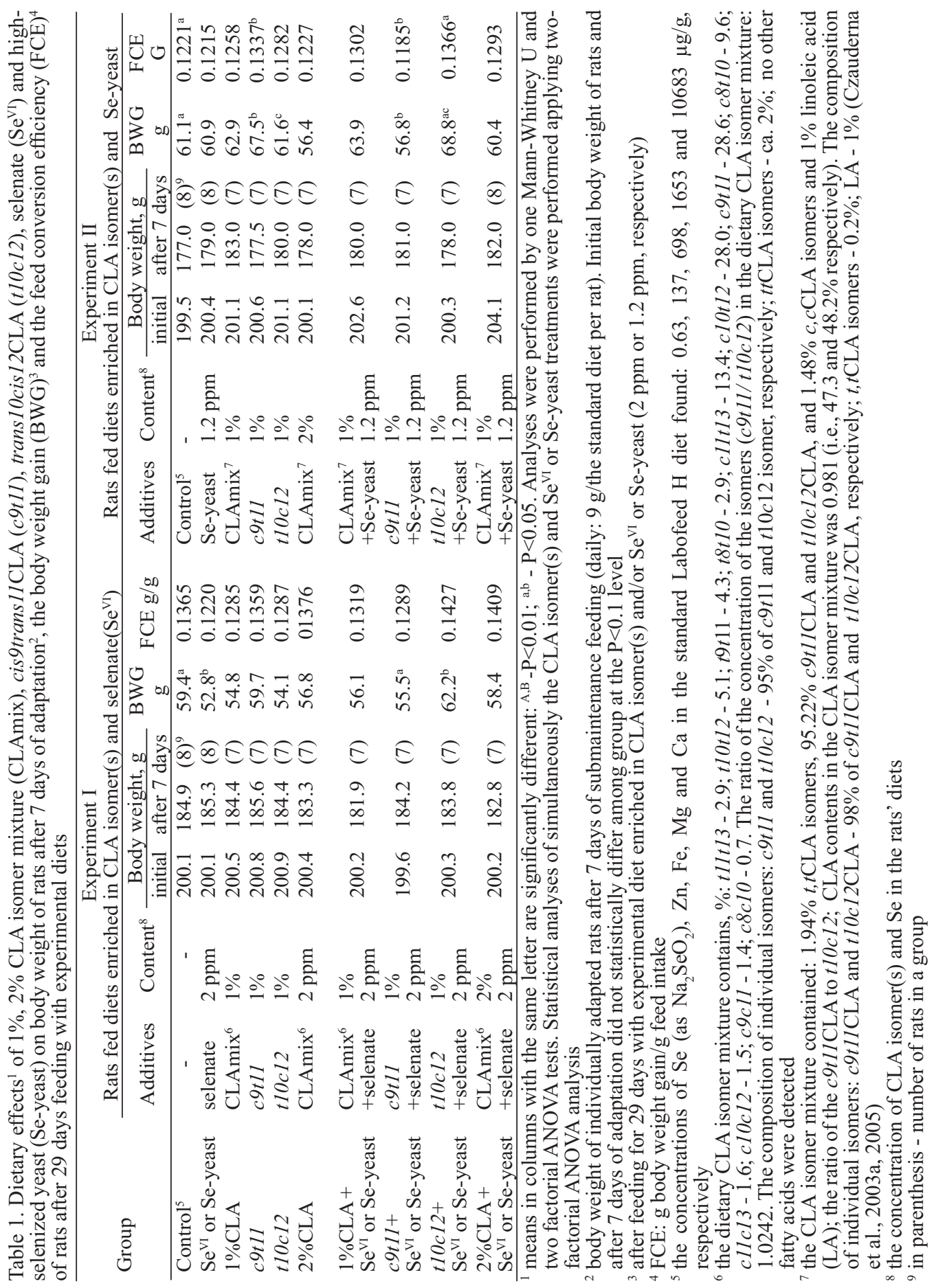


includingdichloromethane (DCM), $\mathrm{KOH}, \mathrm{NaOH}, \mathrm{Na}_{2} \mathrm{SO}_{4}$ and concentrated $\mathrm{HCl}$, were analytical grade and were purchased from POCh (Gliwice, Poland).

\section{Chromatographic equipment}

An alliance separation module (model 2690, Waters) with a Waters 996 photodiode array detector (DAD) and Waters 474 fluorescence detector (FD) was used for determination of the concentration of free amino acids (AAs) and fatty acids in assayed blood plasma samples.

The underivatized CLA isomers and other fatty acids containing conjugated double bonds (CFA) in blood plasma of rats fed all experimental diets were determined according to Czauderna et al. (2003). The derivatized non-CLA fatty acids (FAs) in plasma of rats fed the diets enriched in CLA isomer(s) and $\mathrm{Se}^{\mathrm{VI}}$ (selenate) were determined using an HPLC system according to Czauderna and Kowalczyk (2001). Methylated non-CLA FAs in plasma of rats fed the diets enriched in CLA isomer(s) and high-selenized yeast (Se-yeast) were determined using long-capillary gas-liquid chromatography (GLC) with a flame-ionization detector (FID) (Czauderna et al., 2005).

The method of free amino acid (AAs) conversion to o-phthaldialdehyde (OPA)-derivatives (OPA-AAs) followed by reversed-phase HPLC separations and quantifications of OPA-AAs in plasma of rats fed the all experimental diets were as previously described (Czauderna et al., 2002; Niedźwiedzka et al., 2006c).

\section{Statistical analysis}

The results in Tables 1-6 are presented as means of 7-8 individually analysed rat body parameters, and liver, femoral muscle, and plasma blood samples. Statistical analyses of the effects of the CLA isomer(s) and/or Se (as $\mathrm{Se}^{\mathrm{VI}}$ or Se-yeast) in the diets were conducted using the nonparametric Mann-Whitney $\mathrm{U}$ test for comparing pairs in an independent experimental group (single-factor analysis), while statistical analyses of the interaction between the CLA isomer(s) and $\mathrm{Se}$ (as $\mathrm{Se}^{\mathrm{VI}}$ or Se-yeast) were performed using two-factorial ANOVA (CLA isomer(s) $\times \mathrm{Se})$. The statistical analyses were performed using the Statistica ver. 6 package (Statistica, 2002). Differences were considered significant at the $\mathrm{P}<0.05$ or $\mathrm{P}<0.01$ level, while tendencies, at the $\mathrm{P}<0.1$ level. Statistical analyses of the interaction between the CLA isomer and Se were performed using two-factorial ANOVA analysis (the CLA isomer $(\mathrm{s}) \times \mathrm{Se}$ ); $*_{-} \mathrm{P}<0.05$ and $*^{*}$ - $\mathrm{P}<0.01$ were considered statistically significant. 


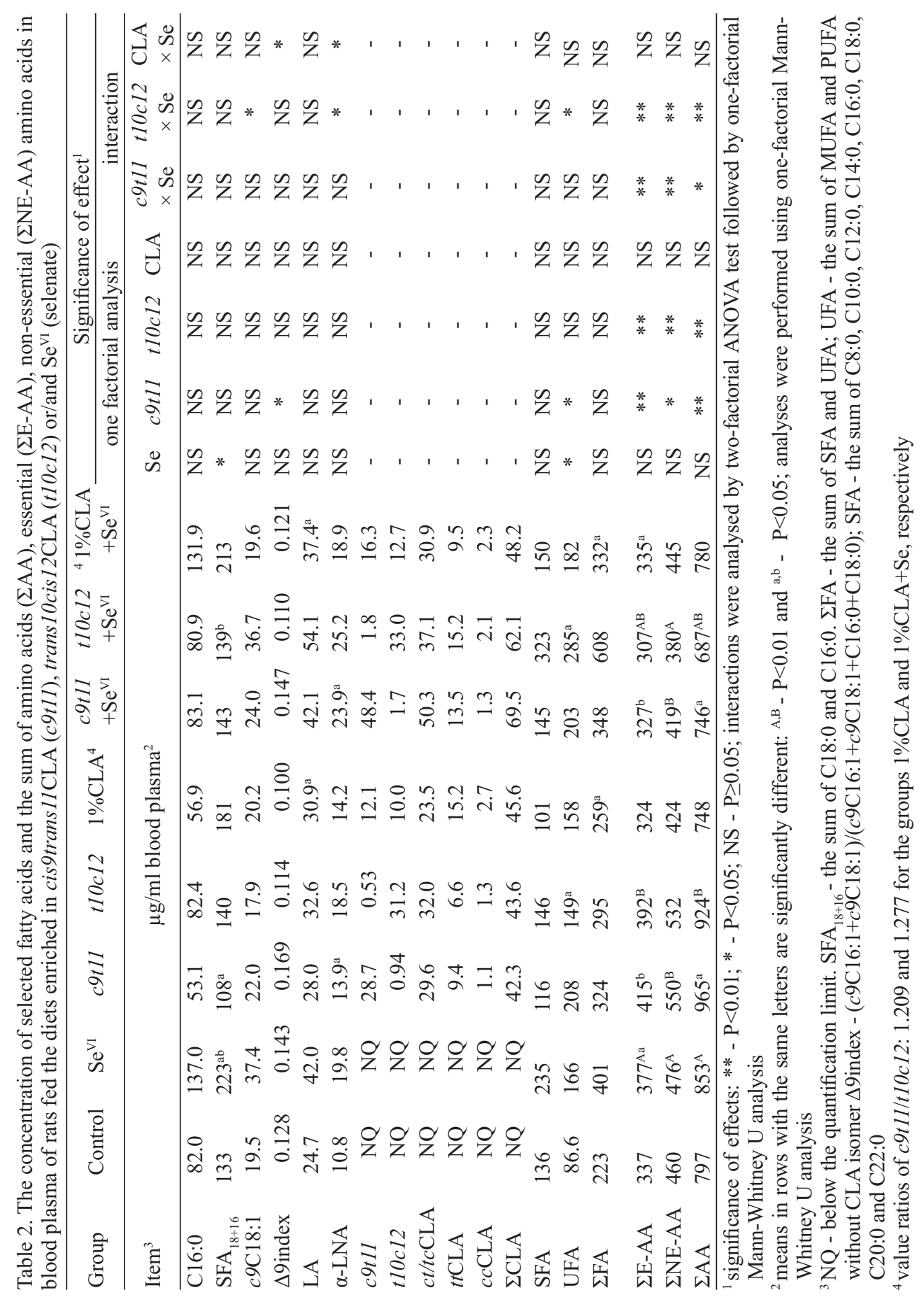




\section{RESULTS AND DISCUSSION}

\section{Feed conversion efficiency, body weight gain of rats}

It is well established that Se as inorganic Se (particularly selenate) is less effectively accumulated in the body of laboratory rats in comparison with dietary organic Se (e.g., Se-cysteine, methionine or Se-yeast) (Lyons and Jacques, 2004; Rayman, 2004). Therefore, in the current study, the concentration of Se as selenate in the rats' diets was higher than the dietary concentration of organic Se as highselenized yeast (i.e. 2 ppm vs $1.2 \mathrm{ppm}$, respectively).

No macroscopic lesions or toxic symptoms of CLA isomers, selenate and Seyeast were observed in the animals fed experimental diets. The diet containing $2 \mathrm{ppm}$ of Se would not be toxic for rodents like rats or mice because only dietary inorganic Se compounds, selenite in particular, chronically consumed at a rate of more than $5 \mathrm{ppm}$ can be hepatotoxic and teratogenic in humans and animals (Tapiero et al., 2003; Tinggi, 2003). The value of $\mathrm{LD}_{50}$ is about $5 \mathrm{mg} \mathrm{Se} / \mathrm{kg}$ of body mass for rats, thus, this correspond to a diet containing $\sim 50 \mathrm{ppm}$ Se (i.e. $20 \mathrm{~g}$ of the Labofeed $\mathrm{H}$ diet enriched in $50 \mathrm{ppm}$ Se per rat and day). In contrast to selenate and particularly selenite, Se-Met (the main Se-compound in Se-yeast) is less reactive because tRNA ${ }_{\text {Met }}$ does not discriminate between Se-Met and methionine (Met). Therefore, the Se-Met residue in general proteins is a stable and safe-storage mode for Se in the body of rats fed the diet enriched in $1.2 \mathrm{ppm} \mathrm{Se}$ as Se-yeast.

In the current study, the influence of dietary CLA isomer(s) and/or Se (as $\mathrm{Se}^{\mathrm{VI}}$ and Se-yeast) on the body weight gain (BWG) of rats and feed conversion efficiency (FCE) was confirmed as being the highest in animals fed the diet enriched simultaneously in $t 10 c 12$ and $\mathrm{Se}^{\mathrm{VI}}$ or Se-yeast (Table 1). Interestingly, the addition of organic Se (as Se-yeast) to the diet with $t 10 c 12$ resulted in a more efficient increase of BWG (11.2\%) of animals and FCE (11.9\%) compared with BWG (4.7\%) of rats and FCE (4.5\%) fed inorganic Se (as selenate) in the diet containing $t 10 c 12$ (i.e. $68.8 \mathrm{~g}$ vs $62.2 \mathrm{~g}$ ). In contrast, the addition of $\mathrm{Se}$ (as $\mathrm{Se}^{\mathrm{VI}}$ and Se-yeast) to the diet enriched in $c 9 t 11$ tended to or statistically significantly decreased the BWG and FCE of rats, although the diet containing $c 9 t 11$ and Se-yeast resulted in the strongest reduction of BWG (-7.0\%) and FCE (-2.95\%). Consistently with these results, the diet containing selenate most efficiently reduced BWG $(-11.1 \%)$ and FCE $(-10.6 \%)$, whereas the diet containing only Se-yeast resulted in a minute decrease in BWG $(-0.33 \%)$ and FCE $(-0.49 \%)$. We also found a tendency towards decreased BWG of rats fed the diet enriched in $2 \%$ CLAmix. Similar results were also reported by Terpstra et al. (2002) and Wahle et al. (2004) in mice and rats. These studies and our recent investigations confirm that CLA isomers decrease the BWG of laboratory animals by increasing energy expenditure and also by increasing energy loss in the excreta (Czauderna et al., 
2004a,b; Niedźwiedzka et al., 2006a; Korniluk et al., 2006, 2007). Consistently, other investigation (Terpstra et al., 2002) reported an elevation in the concentration of insulin and a decrease in the level of leptin in blood plasma of mice fed a diet containing CLA isomers.

\section{CLA isomer concentrations in plasma of rats}

We found that feeding the diets with CLA isomer(s) increased the concentration of CLA isomer(s) in plasma, regardless of the geometrical configuration of CLA isomers (Tables 2, 3 and 5). However, detailed analysis of

Table 3. The concentration of fatty acids in blood plasma of rats fed for 4 weeks $2 \%$ CLA isomer mixture without or with $\mathrm{Se}^{\mathrm{VI}}$ (selenate)

\begin{tabular}{|c|c|c|c|c|c|c|}
\hline \multirow{3}{*}{$\frac{\text { Group }}{\text { Item }^{3}}$} & \multirow{2}{*}{ Control } & \multirow{2}{*}{$\mathrm{Se}(\mathrm{VI})$} & \multirow{2}{*}{$2 \% \mathrm{CLA}^{4}$} & \multirow{2}{*}{$\begin{array}{c}{ }^{4} 2 \% \text { CLA } \\
+\mathrm{Se}^{\mathrm{VI}}\end{array}$} & \multicolumn{2}{|c|}{ Significance of effect ${ }^{1}$} \\
\hline & & & & & \multirow{2}{*}{$2 \%$ CLA } & \multirow{2}{*}{$\begin{array}{c}\text { interaction } \\
2 \% \mathrm{CLA} \times \mathrm{Se} \\
\end{array}$} \\
\hline & \multicolumn{4}{|c|}{$\mu \mathrm{g} / \mathrm{g}$ blood plasma ${ }^{2}$} & & \\
\hline C16:0 & 82.0 & 137 & 61.7 & 92.4 & NS & NS \\
\hline SFA $_{18+16}$ & 133 & 223 & 108 & 147 & NS & NS \\
\hline c9C18:1 & 19.5 & $37.4^{\mathrm{a}}$ & 14.2 & $25.4^{\mathrm{a}}$ & NS & NS \\
\hline$\Delta 9$-index & 0.128 & 0.143 & 0.116 & 0.147 & NS & NS \\
\hline LA & 24.7 & 42.0 & 33.3 & 42.2 & NS & NS \\
\hline$\alpha$-LNA & 10.8 & 19.8 & 18.7 & 22.8 & NS & NS \\
\hline c9t11 & NQ & NQ & 24.3 & 25.5 & - & - \\
\hline$t 10 c 12$ & NQ & NQ & 17.0 & 20.6 & - & - \\
\hline$c t / t c$ CLA & NQ & NQ & 44.1 & 49.0 & - & - \\
\hline$t t$ CLA & NQ & NQ & 13.3 & 16.4 & - & - \\
\hline$c c$ CLA & NQ & NQ & 3.0 & 4.0 & - & - \\
\hline$\Sigma$ CLA & NQ & NQ & 67.3 & 79.8 & - & - \\
\hline SFA & 136 & 235 & 114 & 156 & NS & NS \\
\hline UFA & 86.6 & 166 & 177 & 214 & $*$ & $*$ \\
\hline$\Sigma \mathrm{FA}$ & 223 & 401 & 291 & 370 & NS & NS \\
\hline$\Sigma \mathrm{E}-\mathrm{AA}$ & 337 & $377^{\mathrm{a}}$ & 351 & $314^{\mathrm{a}}$ & NS & $*$ \\
\hline$\Sigma \mathrm{NE}-\mathrm{AA}$ & 460 & 476 & $480^{\mathrm{A}}$ & $405^{\mathrm{A}}$ & NS & NS \\
\hline$\Sigma \mathrm{AA}$ & 797 & 853 & 831 & 719 & NS & NS \\
\hline
\end{tabular}

${ }^{1}$ significance of effects: ${ }^{*} *_{-} \mathrm{P}<0.01,{ }_{-} \mathrm{P}<0.05$; NS-P $\geq 0.05$; interactions were analysed by twofactorial ANOVA test

${ }^{2}$ means in rows with the same letters are significantly different: ${ }^{\mathrm{A}, \mathrm{B}}-\mathrm{P}<0.01{ }^{\mathrm{a}, \mathrm{b}}-\mathrm{P}<0.05$

${ }^{3}$ abbreviations for FA and other items see Table 2

${ }^{4}$ value ratios of $c 9 t 11 / 110 c 12$ : 1.426 and 1.234 for the groups $2 \%$ CLA and $2 \%$ CLA+Se, respectively 


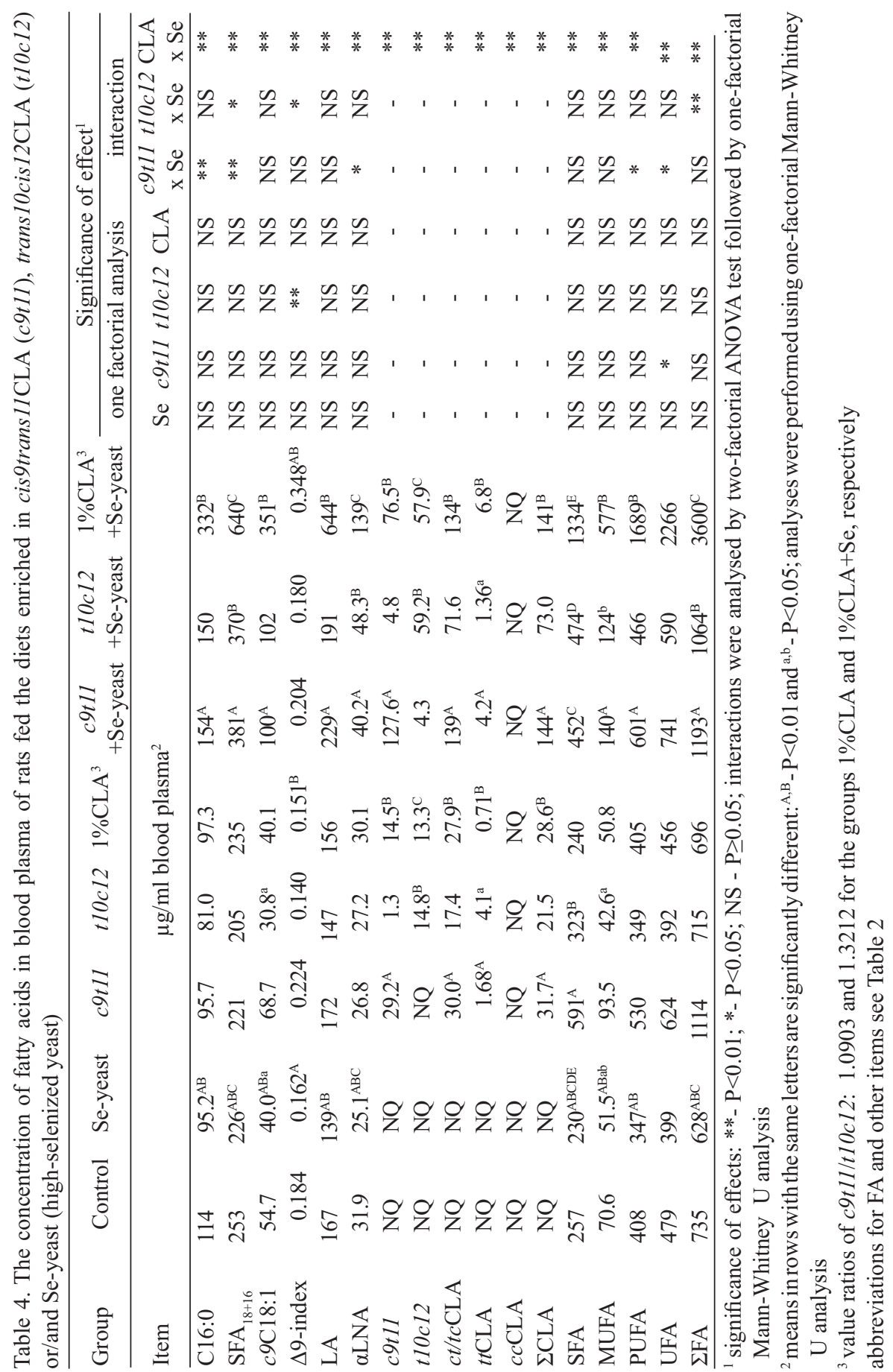


Table 5. The concentration of fatty acids in blood plasma of rats fed for 4 weeks $2 \%$ CLA isomer mixture without or with Se-yeast

\begin{tabular}{|c|c|c|c|c|c|c|}
\hline \multirow{2}{*}{ Group } & \multirow{2}{*}{ Control } & \multirow{2}{*}{ Se-yeast } & \multirow{2}{*}{$2 \% \mathrm{CLA}^{4}$} & \multirow{2}{*}{$\begin{array}{c}2 \% \text { CLA } \\
+ \text { Se-yeast }{ }^{4}\end{array}$} & \multicolumn{2}{|c|}{ Significance of effect ${ }^{1}$} \\
\hline & & & & & \multirow{2}{*}{$2 \% \mathrm{CLA}$} & \multirow{2}{*}{$\begin{array}{c}\text { interaction } \\
2 \% \mathrm{CLA} \times \mathrm{Se}\end{array}$} \\
\hline Item $^{3}$ & & $\mu \mathrm{g} / \mathrm{g}$ blo & d plasma $^{2}$ & & & \\
\hline C16:0 & 114 & $95.2^{\mathrm{A}}$ & 119 & $142^{\mathrm{A}}$ & NS & $* *$ \\
\hline C18:0 & 139 & $131^{\mathrm{A}}$ & 164 & $218^{\mathrm{A}}$ & NS & $*$ \\
\hline SFA $_{18+16}$ & 253 & 226 & 283 & 360 & NS & $* *$ \\
\hline C9C18:1 & 54.7 & $40.0^{\mathrm{a}}$ & 59 & $55^{\mathrm{a}}$ & NS & NS \\
\hline$\Delta 9$-index & 0.184 & 0.162 & 0.156 & 0.144 & NS & NS \\
\hline LA & 167 & $139^{\mathrm{A}}$ & 227 & $199^{\mathrm{A}}$ & NS & NS \\
\hline$\alpha$ LNA & 31.9 & $25.1^{\mathrm{A}}$ & 43.4 & $48.3^{\mathrm{A}}$ & NS & $*$ \\
\hline c9t11 & NQ & NQ & $17.8^{\mathrm{a}}$ & $43.1^{\mathrm{a}}$ & - & - \\
\hline$t 10 c 12$ & NQ & NQ & $14.8^{\mathrm{A}}$ & $30.4^{\mathrm{A}}$ & - & - \\
\hline$c t / t c \mathrm{CLA}$ & NQ & NQ & $32.6^{\mathrm{a}}$ & $73.5 \mathrm{a}$ & - & - \\
\hline$t t$ CLA & NQ & NQ & 1.48 & 4.7 & - & - \\
\hline$c c \mathrm{CLA}$ & NQ & NQ & NQ & 1.04 & - & - \\
\hline$\Sigma$ CLA & NQ & NQ & $34.1^{\mathrm{a}}$ & $79.3^{\mathrm{a}}$ & - & - \\
\hline SFA & 257 & $230^{\mathrm{A}}$ & $340^{\mathrm{a}}$ & $509^{\mathrm{Aa}}$ & NS & $*$ \\
\hline MUFA & 70.6 & $51.5^{\mathrm{A}}$ & 75.8 & $144^{\mathrm{A}}$ & NS & NS \\
\hline PUFA & 408 & $347^{\mathrm{A}}$ & 647 & $499^{\mathrm{A}}$ & NS & NS \\
\hline UFA & 479 & 399 & 723 & 643 & NS & NS \\
\hline$\Sigma F A$ & 735 & $628^{\mathrm{A}}$ & 1063 & $1152^{\mathrm{A}}$ & NS & NS \\
\hline
\end{tabular}

${ }^{1}$ significance of effects: $*^{*} *_{-} \mathrm{P}<0.01, *_{-} \mathrm{P}<0.05$; NS-P $\geq 0.05$; interactions were analysed by twofactorial ANOVA test

${ }^{2}$ means in rows with the same letters are significantly different: ${ }^{\mathrm{A}, \mathrm{B}}-\mathrm{P}<0.01$; ${ }^{\mathrm{a}, \mathrm{b}}-\mathrm{P}<0.05$

${ }^{3}$ abbreviations for FA and other items see Table 2

${ }^{4}$ value ratios of $c 9 t 11 / t 10 c 12$ : 1.2027 and 1.4178 for the groups $2 \%$ CLA and $2 \%$ CLA+Se, respectively

our results revealed a slight preference towards accumulation of c9t11 in comparison with $t 10 c 12$ in the plasma of rats fed the diets enriched in 1 or $2 \%$ CLAmix, irrespective of the presence of $\mathrm{Se}$ (as $\mathrm{Se}^{\mathrm{VI}}$ and Se-yeast). Indeed, the concentration of $t 10 \mathrm{c} 12$ as well as $t 10 t 12$ isomers tended to be lower than $c 9 t 11$ and $t 9 t 11$ isomers in tissues of rats due to more efficient $\beta$-oxidation of t10c12 and t10t12 isomers than their 9,11 homologues (Alasnier et al., 2002; Czauderna et al., 2004a,b). Therefore, the value of the concentration ratios of c9t11/t10c12 in the plasma of rats fed the diets enriched in 1 or $2 \%$ CLAmix, irrespective of the presence of $\mathrm{Se}$ (as $\mathrm{Se}^{\mathrm{VI}}$ and Se-yeast), was higher compared with the value of the concentration ratios of these isomers in the dietary CLAmix (see data in Tables 2-5 vs Table 1). Addition of $\mathrm{Se}^{\mathrm{VI}}$ to the diet enriched in $1 \%$ CLAmix stimulated $\beta$-oxidation of $t 10 c 12$ in plasma. On the other hand, the higher concentration of CLAmix in the diet enriched in $\mathrm{Se}^{\mathrm{VI}}$ disturbed the 
$\beta$-oxidation of $t 10 c 12$ in comparison with the $\beta$-oxidation of this isomer in the blood of rats fed the diet enriched in only $2 \%$ CLAmix (Tables 2 and 3). The different chemical forms of Se may have different metabolic roles (Tapiero et al., 2003; Suzuki, 2005), as observed in our previous studies (Czauderna et al., 2004a,b; Korniluk et al., 2006). Indeed, in our current investigation we found that dietary Se-yeast (a rich-source of seleno-methionine) significantly stimulated $\beta$-oxi-dation of $t 10 c 12$ regardless of the amount of CLAmix added to the diets (Tables 4 and 5). Moreover, as can be seen from the results summarized in Tables 2-5, the addition of organic Se as Se-yeast to the diets enriched in CLA isomer(s) resulted in significantly stronger stimulation of the accumulation of CLA isomer(s) in plasma in comparison with $\mathrm{Se}^{\mathrm{VI}}$ supplied to the diets containing CLA isomer(s). Different chemical forms of dietary $\mathrm{Se}$ (as $\mathrm{Se}^{\mathrm{VI}}$ or Se-yeast) could be attributed to the different influence of Se additives to the diets on the profile and yield of the accumulation of CLA isomers in plasma of rats. Indeed, selenate $\left(\mathrm{Se}^{\mathrm{VI}}\right)$, unlike selenite $\left(\mathrm{Se}^{\mathrm{IV}}\right)$, is metabolized in the liver to give selenide, seleno-diglutathione, seleno-cysteine (Se-Cys), etc. (Combs, 2004; Suzuki, 2005). Therefore, Se-Cysproteins are the predominant Se-compound in blood plasma of rats fed diets enriched in $\mathrm{Se}^{\mathrm{VI}}$. On the other hand, dietary Se-yeast stimulated accumulation of Se-Cys-proteins and, particularly, seleno-methionine-proteins in the body of rats (Suzuki, 2005). Therefore, these changes in the profile and concentration of CLA isomer(s) could be attributed to the higher concentration of seleno-methionineproteins in the plasma of rats.

\section{Effect of CLA isomer(s) and Se on the concentration of non-conjugated fatty acids in plasma}

The current study was designed to determine whether changes of the concentration of non-conjugated fatty acids depended upon the chemical form of dietary Se and the positional and geometrical structure of CLA isomers. As can be seen from the results summarized in Tables 2-5, the dietary 1\% CLAmix showed a tendency towards decreasing the concentration of $\mathrm{C} 16: 0$ and the sum of all assayed saturated fatty acids (SFA) in plasma. Unexpectedly, the diets enriched in 1 or $2 \%$ CLAmix and $\mathrm{Se}$ (as $\mathrm{Se}^{\mathrm{VI}}$ or Se-yeast) tended or statistically significantly increased

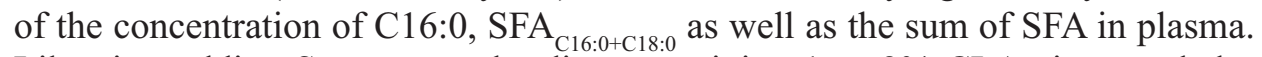
Likewise, adding Se-yeast to the diets containing 1 or $2 \%$ CLAmix revealed a similar effect on these saturated fatty acids, although the influence of dietary highselenized yeast was considerably stronger (Tables 2 and 3 vs 4 and 5). Dietary Se-yeast more efficiently stimulated the accumulation these saturated fatty acids in plasma of rats fed the diets enriched in $c 9 t 11$ or $t 10 c 12$ compared with rats fed the diets containing $\mathrm{Se}^{\mathrm{VI}}$ and $c 9 t 11$ or $\mathrm{Se}^{\mathrm{VI}}$ and $t 10 c 12$. On the other hand, the diet enriched in only Se-yeast showed a tendency towards a slight decrease in the 
concentration of these saturated fatty acids in plasma, whereas dietary $\mathrm{Se}^{\mathrm{VI}}$ tended to or statistically significantly increased the concentration of these fatty acids. The obtained results documented that inorganic Se as selenate stimulated the accumulation of saturated fatty acids in plasma, while Se-yeast, mainly as selenomethionine, lowered the yield of saturated fatty acid formation in rat plasma.

Dietary CLA isomers exert a variety of influences on the capacity of $\Delta 9$-desaturation of fatty acids (Belury, 2002; Wahle at al., 2004). Indeed, the value of the desaturase index $(\Delta 9$-index $)$ as well as the concentration of $c 9 \mathrm{C} 18: 1$ tended to decrease in the plasma of rats fed the diet enriched in $t 10 c 12$ or 1\% CLAmix, regardless of the presence of $\mathrm{Se}^{\mathrm{VI}}$ (Tables 2-5), whereas the addition of Se-yeast to the diet containing these isomers almost eliminated this effect of dietary $t 10 \mathrm{cl} 2$ (Table 4). This is in agreement with our previous studies (Czauderna et al., 2004a,b; Korniluk et al., 2006; Niedźwiedzka et al., 2006a) in which dietary $t 10 c 12$ also reduced the $\Delta 9$-desaturation activity and inhibited steaoryl-CoA desaturase mRNA expression and fatty acid synthesis in rats (Terpsta, 2004). Terpsta (2004) explained that a 12-double bond appears to be a key structure for inhibiting stearoyl-CoA desaturase activity, especially when coupled with a 10-double bond, however not with a 9-double bond (Belury, 2002). On the other hand, the diet containing c9t11 tended to increase the value of the $\Delta 9$-index as well as the concentration of $c 9 \mathrm{C} 18: 1$ in plasma, whereas addition of this isomer to the diets enriched in $\mathrm{Se}$ (as $\mathrm{Se}^{\mathrm{VI}}$ and Se-yeast) tended to increase the concentration of $c 9 \mathrm{C} 18: 1$ in plasma compared with the concentration of this isomer in plasma of rats fed the diets containing only $c 9 t 11$. So, these results show that simultaneous addition of $c 9 t 11$ and $\mathrm{Se}$ (as $\mathrm{Se}^{\mathrm{VI}}$ and $\mathrm{Se}$-yeast) to the diets stimulated $\Delta 9$-desaturation activity or/ and increased steaoryl-CoA desaturase mRNA expression in the body of rats.

We found that feeding $\mathrm{Se}$ as $\mathrm{Se}^{\mathrm{VI}}$ and Se-yeast usually tended to increase, or significantly increased, the concentration of linoleic (LA) and linolenic (LNA) acids in plasma of rats fed the diets containing CLA isomer(s) and Se regardless of its chemical form (a positive interaction) (Tables 2-5). A significantly higher increase of the concentrations of LA and LNA was observed in plasma of rats fed the diets enriched in CLA isomer(s) and Se-yeast, despite the diet enriched in only Se-yeast tending to decrease the concentrations of LA, LNA as well as MUFA, PUFA and the sum of unsaturated fatty acids (UFA) as well as the sum of all assayed fatty acids ( $\Sigma F A)$ in plasma (Tables 4 and 5). A similar effect was observed in the liver, spleen and pancreas of rats fed the diet enriched in only Se-yeast (Korniluk et al., 2006, 2007). The positive correlation between the concentration of the sum of UFA (i.e. MUFA and PUFA) and simultaneous addition of CLA isomer(s) and $\mathrm{Se}$ (as $\mathrm{Se}^{\mathrm{VI}}$ and Se-yeast) to the diet was observed in plasma of rats. As expected, the addition of Se-yeast together with CLA isomer(s) caused a significantly higher increase in the concentration of UFA in plasma than the addition of $\mathrm{Se}^{\mathrm{VI}}$ and CLA isomer(s). These results are consistent with our recent 
investigation in rats showing that the interaction between Se-yeast and CLA isomer(s) was also responsible for stimulating the accumulation of LA, LNA as well as other PUFA in spleen, pancreas and kidneys of rats fed the diets containing Se-yeast and CLA isomer(s) (Korniluk et al., 2006, 2007). The explanation for the interaction mechanism of the increase in the concentration of unsaturated fatty acids, particularly long-chain PUFA (Tables 4 and 5), is through the increase of the capacity of $\Delta 9-, \Delta 6-, \Delta 4$-desaturations and elongation of fatty acids. As a consequence of the above observations, feeding CLA isomer(s), particularly with $\mathrm{Se}$ (as $\mathrm{Se}^{\mathrm{VI}}$ or Se-yeast), has been shown to usually increase the sum of all assayed fatty acids in plasma of rats.

\section{Concentrations of amino acids in plasma, liver and femoral muscles of rats}

Our recent investigations (Czauderna et al., 2004a,b; Niedźwiedzka et al., 2006b) as well as other studies (Alasnier et al., 2002; Terpstra et al., 2002; Wahle et al., 2004) indicated that CLA isomers decreased body fat, increased lean body mass and the amount of protein in the body of laboratory animals. In the presented study, the concentrations of amino acids in blood plasma (Tables 2 and 3), liver and femoral muscles (Table 6) were also affected by the diets enriched in CLA isomer(s). The diet containing individual CLA isomers increased the concentration of the sum of essential ( $\Sigma \mathrm{E}-\mathrm{AA})$ and non-essential ( $\Sigma \mathrm{NE}-\mathrm{AA})$ amino acids in plasma (Table 2). On the other hand, the addition of 1\% of the CLA isomer mixture to the diet showed a tendency to decrease the concentration of these fatty acids in plasma. This result suggests that the interaction between dietary c9t11 and $t 10 c 12$ in rats resulted in reducing the concentration of $\Sigma \mathrm{E}-\mathrm{AA}$ and $\Sigma \mathrm{NE}-\mathrm{AA}$ in plasma. Increasing the concentration of the CLAmix in the diet diminished this antagonistic effect of the isomer mixture in rats; consequently, the diet containing $2 \%$ CLAmix showed a tendency to slightly increase the concentration of these fatty acids (Table 3 ).

Addition of $\mathrm{Se}^{\mathrm{VI}}$ to the diet enriched in individual isomers decreased the concentration of $\Sigma \mathrm{E}-\mathrm{AA}$ and $\Sigma \mathrm{NE}-\mathrm{AA}$ in plasma compared with rats fed the diet enriched in only the individual isomer (Table 2). Similarly, the antagonistic interaction between dietary $\mathrm{Se}^{\mathrm{VI}}, c c, t t, c 9 t 11$ and $t 10 c 12$ CLA isomers decreased the effect of individual CLA isomers and $\mathrm{Se}^{\mathrm{VI}}$ (Tables 2 and 3 ) on the concentration of these amino acids. Consequently, the concentrations of $\Sigma \mathrm{E}-\mathrm{AA}$ and $\Sigma \mathrm{NE}-\mathrm{AA}$ in plasma were similar to the concentration of these fatty acids in the plasma of control rats.

The antagonism between dietary geometrical configuration of CLAisomer(s) and $\mathrm{Se}^{\mathrm{VI}}$ was also reflected in the concentration of these fatty acids in the liver and femoral muscle (Table 6). The diet enriched in CLA isomer(s) and $\mathrm{Se}^{\mathrm{VI}}$ resulted in a small numerical decrease in the concentration of $\Sigma \mathrm{E}-\mathrm{AA}$ in the liver and muscle and in the 


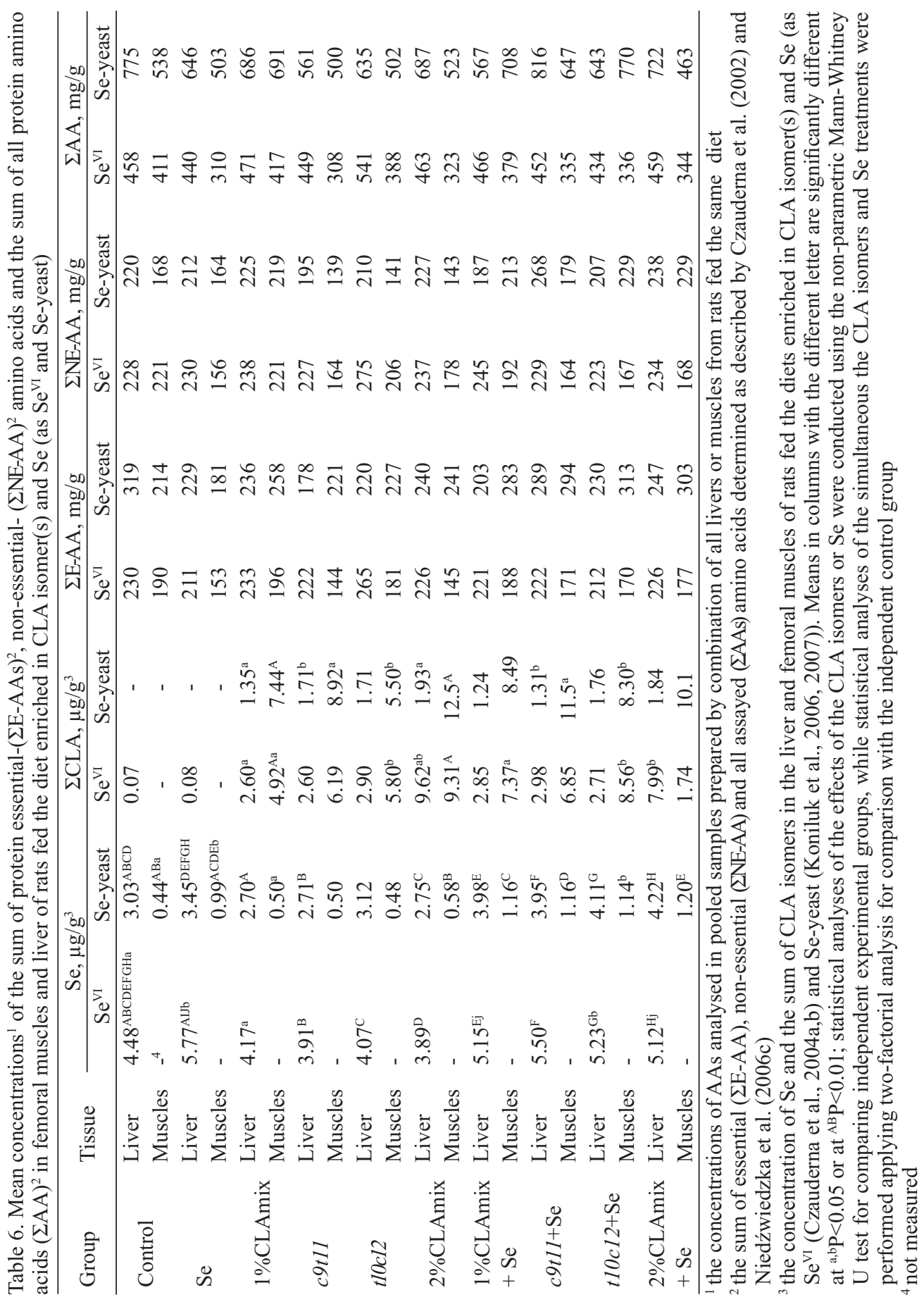


concentration of $\Sigma$ NE-AA in muscles of rats fed the diet containing CLA isomer(s) and $\mathrm{Se}^{\mathrm{VI}}$. Similarly, a numerical decrease of the concentration of $\Sigma \mathrm{E}-\mathrm{AA}$ was also observed in the liver of rats receiving the diets enriched in Se-yeast and CLA isomer(s). A similar effect, although weaker, was found in the liver of rats fed the diets containing pure CLA isomer(s), i.e. possessing smaller concentrations of $t t$ CLA and $c c$ CLA (Table 1). The current results confirm those of our recent investigations and other studies in rodents showing that dietary CLA isomer(s) increased liver weight (up to 50\%); this effect on liver weight of CLA isomer(s) was mainly due to the increase the total lipid content per gram of liver in rats and mice (Terpstra et al., 2002; Czauderna et al., 2004a; Korniluk et al., 2006), while the total protein content in the liver decreased.

The data summarized in Table 6 confirm the results of other studies showing that CLA isomer(s) appear to increase the lean body mass and the amount of protein in the body of laboratory animals (Belury, 2002). Indeed, dietary CLA isomer(s), possessing a lower concentration of $t \mathrm{tCLA}$, numerically stimulated the accumulation of $\Sigma \mathrm{E}-\mathrm{AA}$ in muscles, while decreasing the sum of all amino acids ( $\mathrm{AAA}$ ) (Table 6). This effect on the concentration of $\Sigma \mathrm{E}-\mathrm{AA}$ was stronger in muscles of rats fed the diets containing these CLA isomer(s) and Se-yeast. The obtained results suggest that dietary CLA isomers decreased the biosynthesis of NE-AA, so the mean concentration of $\Sigma \mathrm{NE}-\mathrm{AA}$ in muscles numerically declined; this effect was stronger in the muscles of rats (Table 6) fed the diets enriched in CLA isomer(s) containing a higher level of $t$ CLA and ccCLA isomers (Table 1), irrespective of the presence of $\mathrm{Se}^{\mathrm{VI}}$.

\section{CONCLUSIONS}

As reported in other studies on rodents, the effectiveness of dietary CLA isomers in stimulating the body weight gain of rats and feed conversion efficiency was confirmed in our current study. In it, we also unexpectedly found that the strongest positive interactions on these parameters occurred between $t 10 c 12$ and Se, regardless of the latter's chemical form. Therefore, we hypothesize that these effects can be explained by the interaction between metabolite(s) of dietary $\mathrm{Se}^{\mathrm{VI}}$ and Se-yeast (probably the same ones) and $t 10 c 12$ and/or its metabolite(s). More importantly, we suggest that dietary $\mathrm{Se}^{\mathrm{VI}}$ and Se-yeast increased the capacity of $\beta$-oxidation of $t 10 c 12$ as well as $t 10 t 12$; therefore in our current and previous studies, the $c 9 t 11$ isomer was preferentially accumulated in the body of rats and sheep, especially those fed the diets simultaneously enriched in the mixture of CLA isomers and selenium.

Moreover, we hypothesize that the interaction between dietary CLA isomer(s) and $\mathrm{Se}$ (as $\mathrm{Se}^{\mathrm{VI}}$ or Se-yeast) stimulates the capacity of $\Delta 9-, \Delta 6-, \Delta 4$-desaturation and elongation of fatty acids. 


\section{REFERENCES}

Alasnier C., Berdeaux O., Chardigny J.M., Sébédio J.L., 2002. Fatty acid composition and conjugated linoleic acid content of different tissues in rats fed individual conjugated linoleic acid isomers given as triacylglycerols. J. Nutr. Biochem. 13, 337-345

Arthur J.R., 2003. Selenium supplementation: does soil supplementation help and why? Proc. Nutr. Soc. 62, 393-397

Belury M.A., 2002. Dietary conjugated linoleic acids in health: Physiological effects and mechanisms of action. Annu. Rev. Nutr. 22, 505-531

Combs G.F., 2004. Status of selenium in prostate cancer prevention. Brit. J. Cancer 91, 195-199

Czauderna M., Kowalczyk J., 2001. Separation of some mono-, di- and tri-unsaturated fatty acids containing 18 carbon atoms by high-performance liquid chromatography and photodiode array detection. J. Chromatogr. B 760, 165-178

Czauderna M., Kowalczyk J., Korniluk K., Wassowska I., 2005. Improving the analysis of fatty acids using combination of gas chromatography and $\mathrm{Ag}^{+}$-liquid chromatography. J. Anim. Feed Sci. 14, Suppl. 1, 263-266

Czauderna M., Kowalczyk J., Niedźwiedzka K.M., Wasowska I., 2002. Determination of free- and protein primary amino acids in biological materials by high-performance liquid chromatography and photodiode array detection. J. Anim. Feed Sci. 11, 143-167

Czauderna M., Kowalczyk J., Niedźwiedzka K.M., Wąsowska I., Pastuszewska B., 2004a. Conjugated linoleic acid (CLA) content and fatty acids composition of muscle in rats fed isomers of CLA and selenium. J. Anim. Feed Sci. 13, 183-196

Czauderna M., Kowalczyk J., Niedźwiedzka K.M., Wąsowska I., Pastuszewska B., Bulska E., Ruszczyńska A., 2004b. Liver and body mass gain, content of CLA isomers and other fatty acids in the liver of rats fed CLA isomers and selenium. J. Anim. Feed Sci. 13, 353-369

Czauderna M., Kowalczyk J., Wąsowska I., Niedźwiedzka K.M., 2003. Determination of conjugated linoleic acid isomers by liquid chromatography and photodiode array detection. J. Anim. Feed Sci. 12, 269-282

De La Tore A., Debiton E., Juaneda P., Durand D., Chardigny J-M, Barthomeuf C., Bauchart D., Gruffat D., 2006. Beef conjugated linoloic acid isomers reduce human cancer cell growth even when associated with other beef fatty acids. Brit. J. Nutr. 95, 346-352

Korniluk K., Czauderna M., Kowalczyk J., Mieczkowska A., Taciak M., Leng L'., 2006. Influence of dietary conjugated linoleic acid isomers and selenium on growth, feed efficiency, and liver fatty acid profile in rats. J. Anim. Feed Sci. 15, 131-146

Korniluk K., Kowalczyk J., Czauderna M., 2007. The influence of dietary conjugated linoleic acid isomers and selenized yeast on the fatty acid profile of spleen, pancreas and kidneys of rats. J. Anim. Feed Sci. 16, 121-139

Lyons T.P., Jacques K.A., 2004. Nutritional biotechnology in the feed and food industries. In: Proceedings of Alltech's Twentieth Annual Symposium. Nottingham University Press, Nottingham (UK)

Naumanna E., Carpentier Y.A., Saebo A., Lassel T.S., Chardigny J.-M., Sebedio J.-L., Ronald P., Mensink R.P., 2006. Cis-9,trans-11 and trans-10,cis-12 conjugated linoleic acid (CLA) do not affect the plasma lipoprotein profile in moderately overweight subjects with LDL phenotype B. Atherosclerosis 188, 167-174

Niedźwiedzka K.M., Czauderna M., Kowalczyk J., 2006b. The influence of dietary conjugated linoleic acid isomers on the essential amino acid profile in rats. J. Anim. Feed Sci. 15, Suppl. 1, 69-72

Niedźwiedzka K.M., Czauderna M., Kowalczyk J., 2006c. Reversed-phase liquid chromatography for free and protein amino acids from specimens of animal origin. The XXXth Symposium 
"Chromatographic Methods of Investigating the Organic Compounds". Katowice-Szczyrk (Poland). Book of Abstract, Annex, pp. 32-39

Niedźwiedzka K.M., Wąsowska I., Czauderna M., Kowalczyk J., Pastuszewska B., 2006a. Influence of dietary conjugated linoleic acid isomers and Se on fatty acids profile in blood plasma and some tissues of rats. J. Anim. Feed Sci. 15, 471-489

Pastuszewska B., Ochtabińska A., Morawski A., 2000. A note on the nutritional adequacy of stock diets for laboratory rats and mice. J. Anim. Feed Sci. 9, 533-542

Rayman P.M., 2004. Review article. The use of high-selenium yeast to raise selenium status: how does it measure up? Brit. J. Nutr. 92, 557-573

Statistica by StatSoft, 2002. Web: www.statsoft.pl

Suzuki K.T., 2005. Metabolomics of selenium: Se metabolites based on speciation studies. J. Health Sci. $51,107-114$

Tapiero H., Townsend D.M., Tew K.D., 2003. The antioxidant role of selenium and selenocompounds. Biomed. Pharmacotherapy 57, 134-144

Terpstra A.H.M., 2004. Effect of conjugated linoleic acid on body composition and plasma lipids in humans: an overview of the literature. Amer. J. Clin. Nutr. 79, 352-361

Tinggi U., 2003. Essentiality and toxicity of selenium and its status in Australia: a review. Toxicol. Lett. $137,103-110$

Wahle K.W.J., Heys S.D., Rotondo D., 2004. Conjugated linoleic acids: are they beneficial or detrimental to health? Prog. Lipid Res. 43, 553-587 